Supplement of Biogeosciences, 15, 491-505, 2018

https://doi.org/10.5194/bg-15-491-2018-supplement

(c) Author(s) 2018. This work is distributed under

the Creative Commons Attribution 4.0 License.

(c) (1)

Supplement of

\title{
Annual net primary productivity of a cyanobacteria-dominated biological soil crust in the Gulf Savannah, Queensland, Australia
}

Burkhard Büdel et al.

Correspondence to: Burkhard Büdel (buedel@bio.uni-kl.de)

The copyright of individual parts of the supplement might differ from the CC BY 4.0 License. 

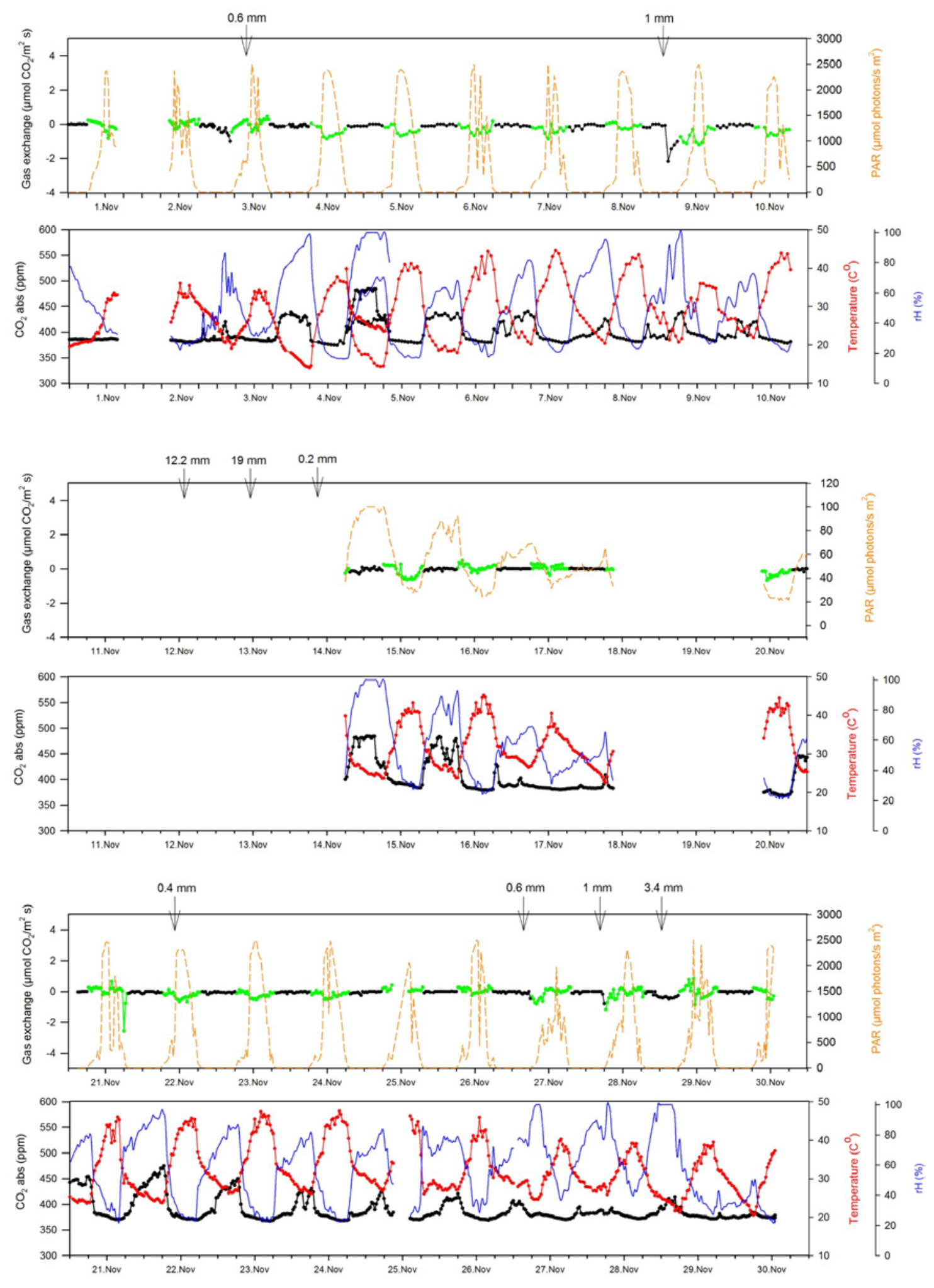

Figure S1 

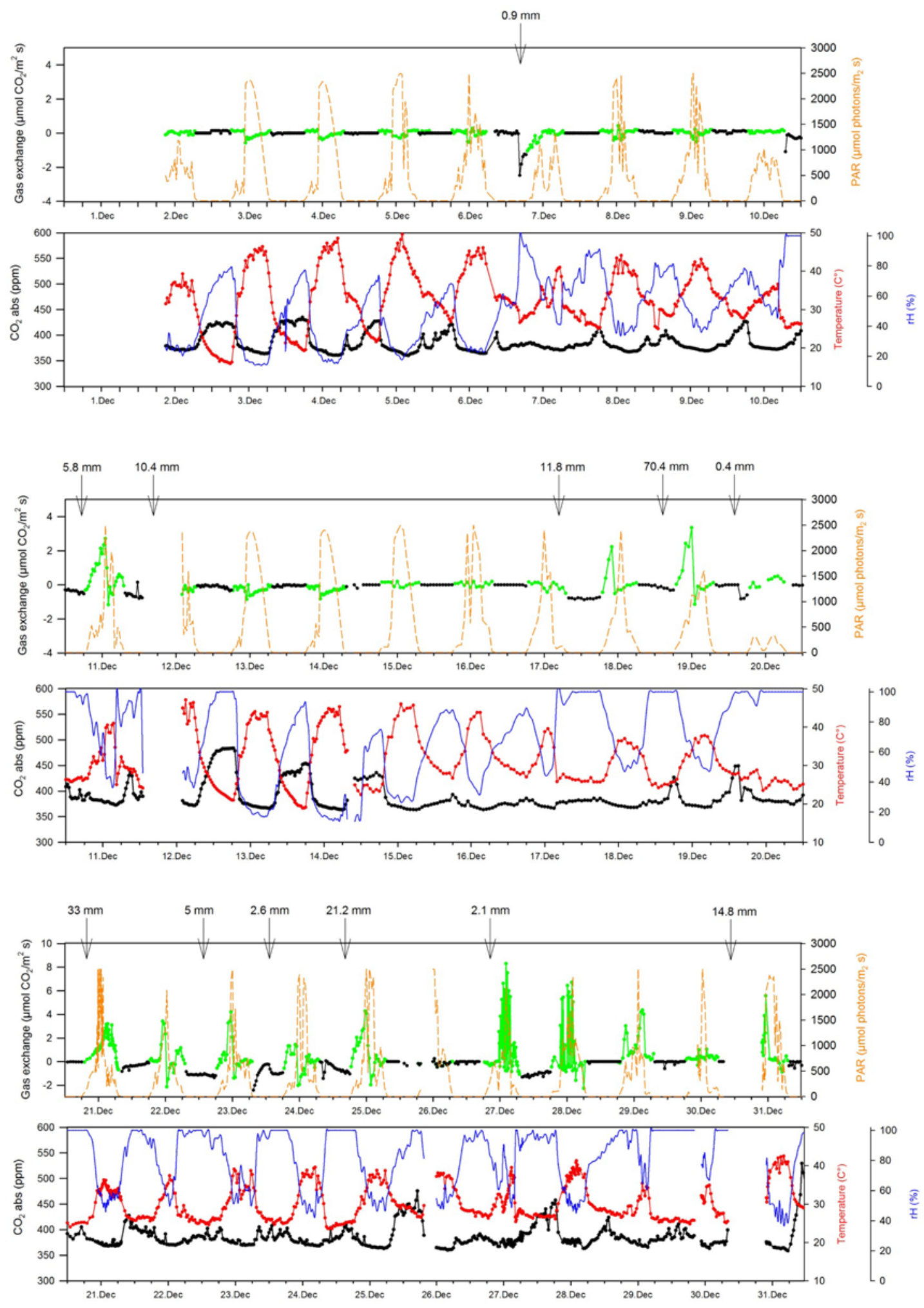

Figure S2 

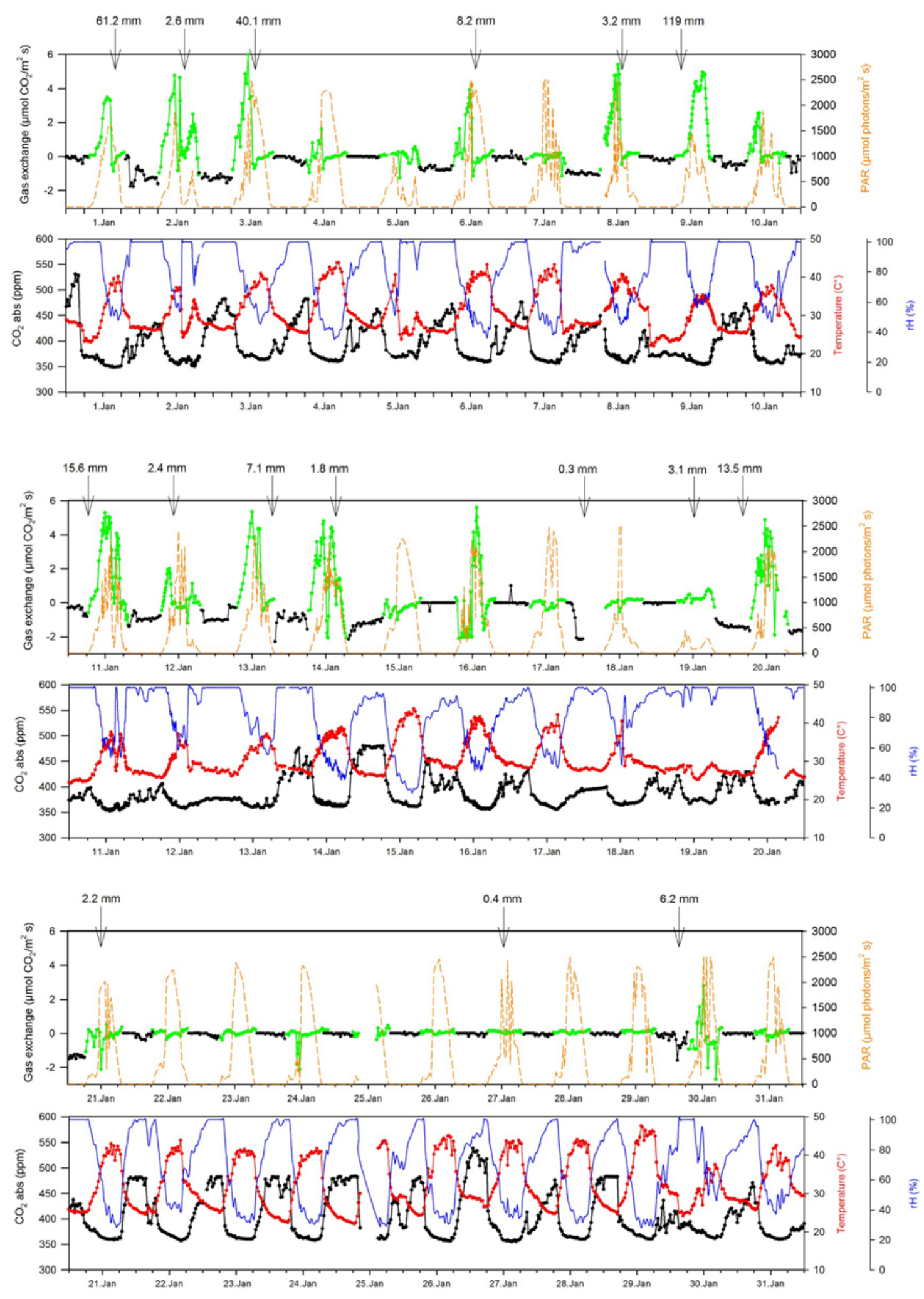

Figure S3 

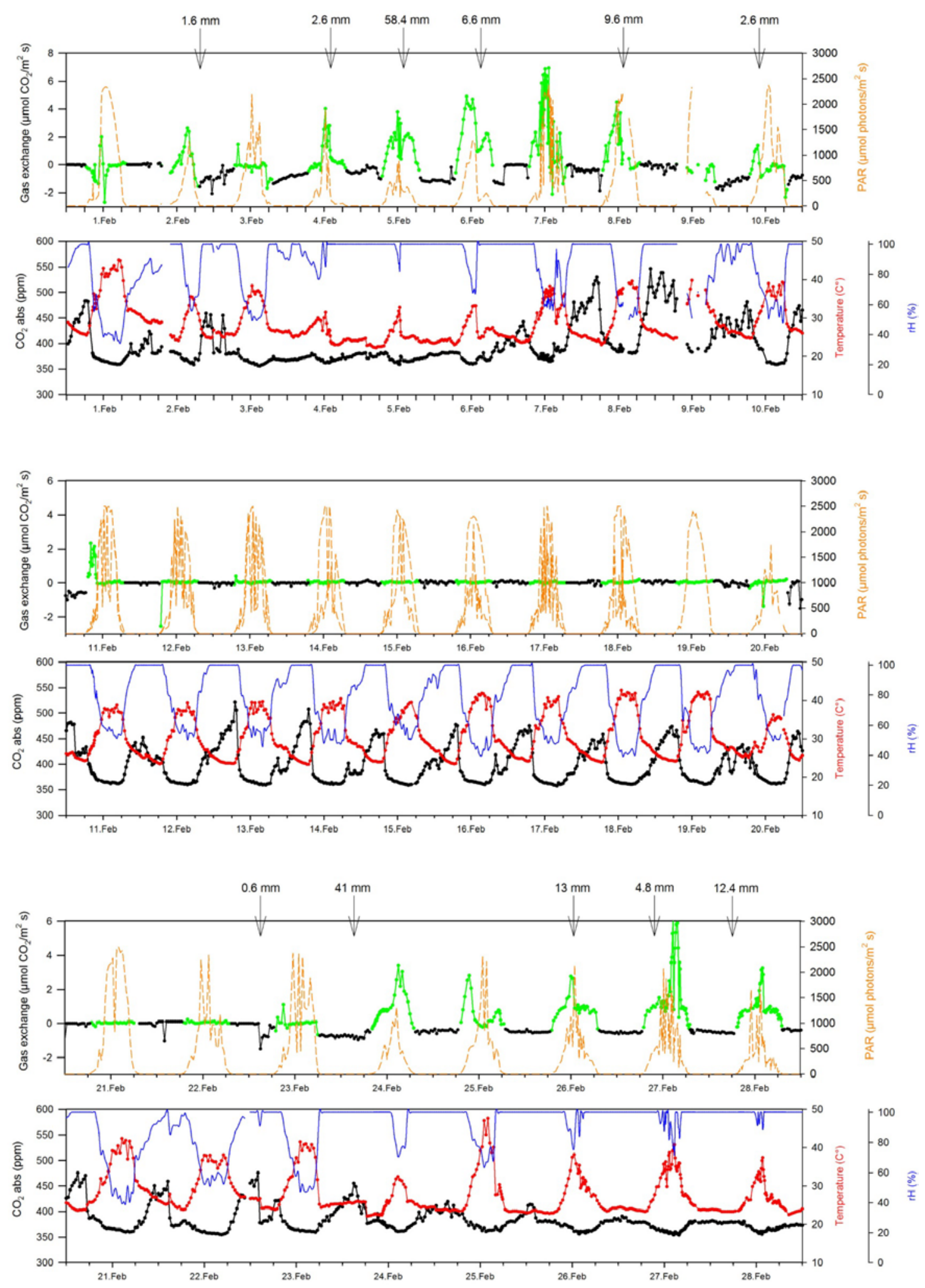

Figure S4 

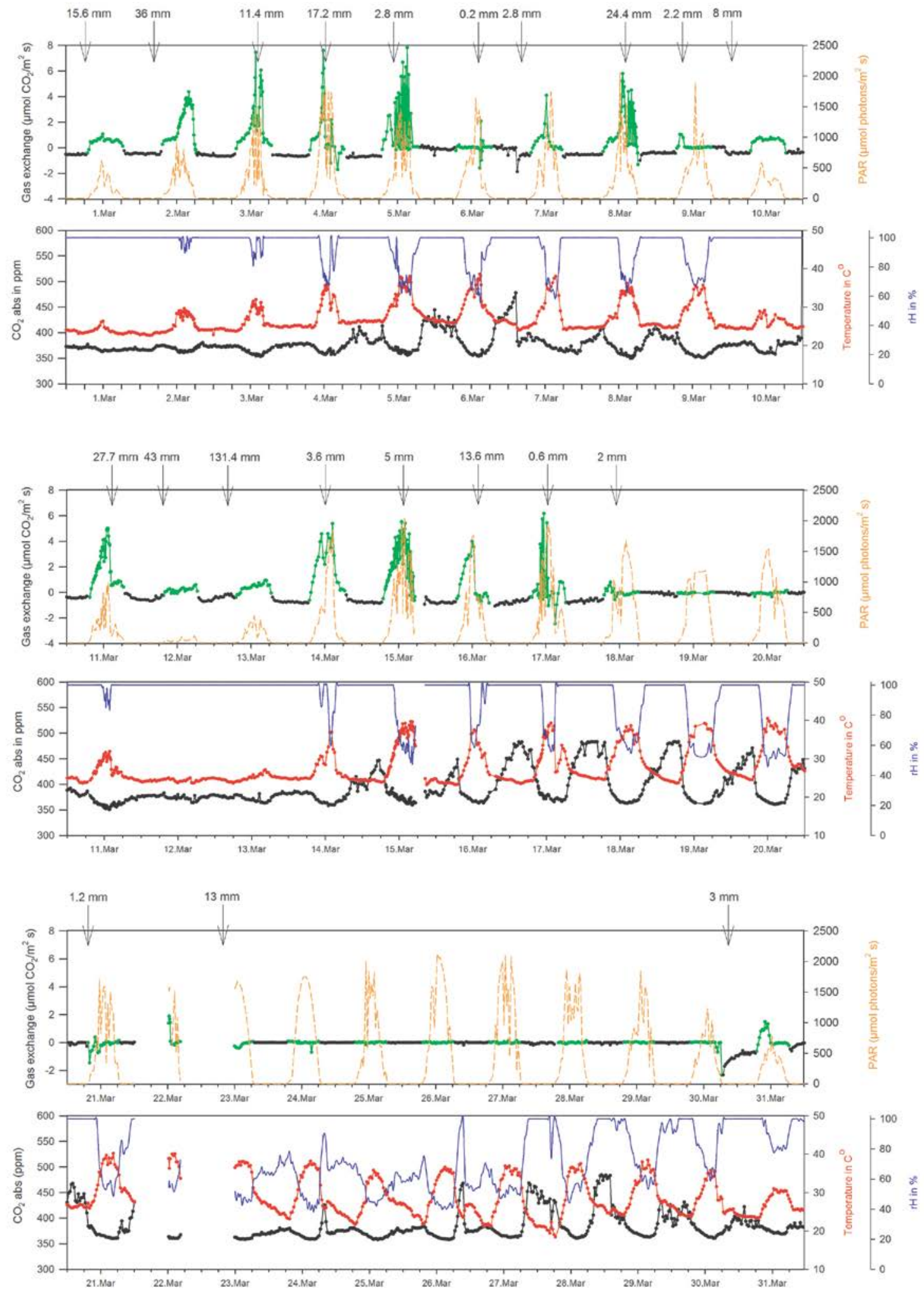

Figure S5 

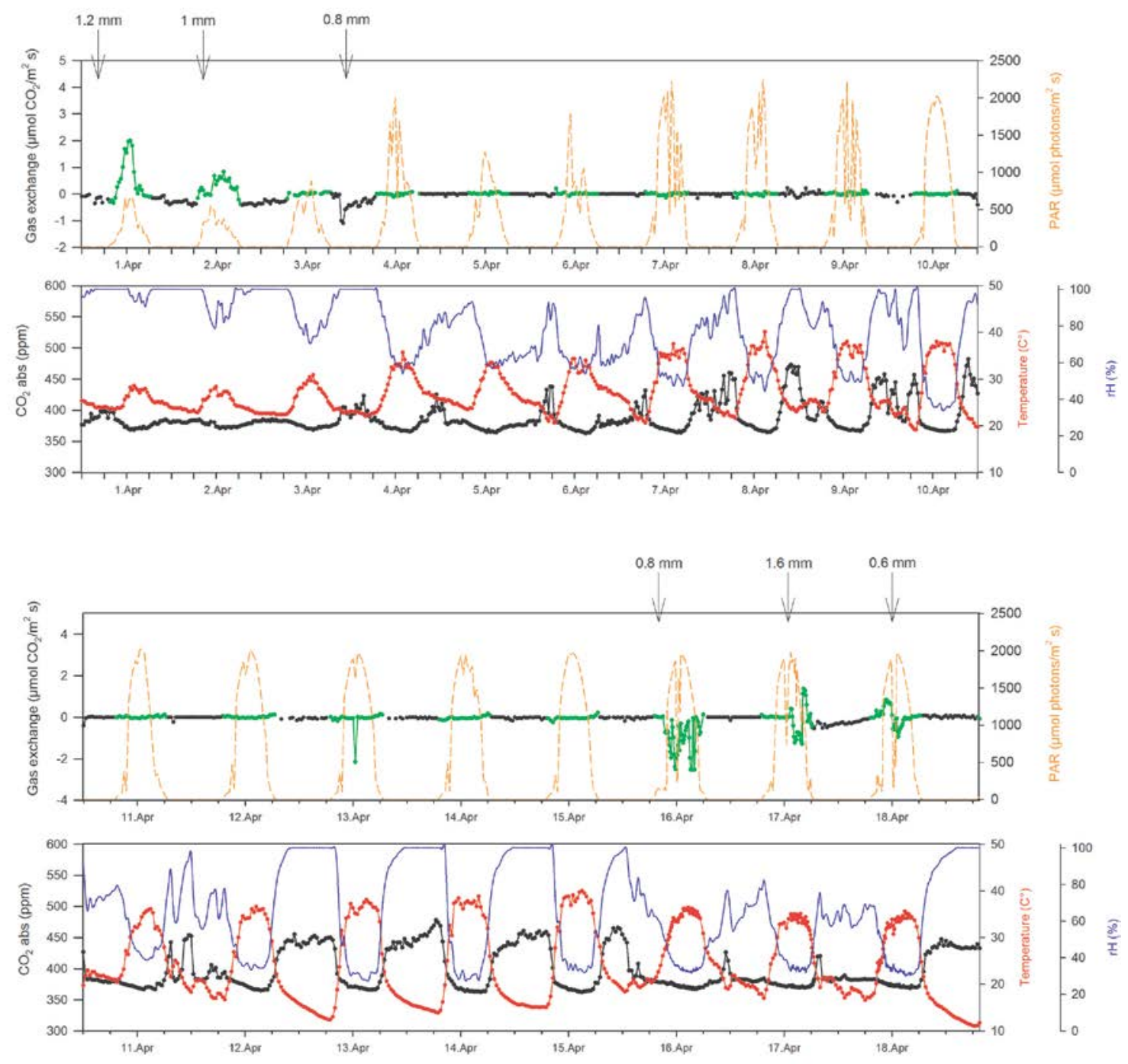

Figure S6 